03

\title{
Расчет аэродинамических характеристик ветроэнергетической установки с лопастями в виде вращающихся цилиндров
}

\author{
(c) Н.К. Танашева ${ }^{1}$, А.Р. Бахтыбекова ${ }^{1}$, Н.Н. Шуюшбаева ${ }^{2}$, А.К. Тусупбекова ${ }^{1}$, А.Ж. Тлеубергенова ${ }^{1}$ \\ ${ }^{1}$ Карагандинский университет им. акад. Е.А. Букетова, Караганда, Казахстан \\ ${ }^{2}$ Кокшетауский университет им. Ш. Уалиханова, Кокшетау, Казахстан \\ E-mail: nazgulya_tans@mail.ru
}

Поступило в Редакцию 7 декабря 2020 г.

В окончательной редакции 1 июля 2021 г.

Принято к публикации 14 июля 2021 г.

\begin{abstract}
Приведены результаты исследований по определению быстроходности ветроэнергетической установки и расчету коэффициента использования энергии ветра вращающегося цилиндра постоянного сечения с гладкой поверхностью. С помощью экспериментальных и теоретических методов проведены исследования основных аэродинамических характеристик эффективности работы ветроэнергетической установки с лопастями в виде вращающихся цилиндров. Изменения аэродинамических параметров потока составляли $2 \mathrm{~m} / \mathrm{s}$ и выше. Результаты показали, что значение коэффициента использования энергии ветра уменьшается с ростом скорости набегающего потока. Экспериментально установлено, что значение быстроходности ветроэнергетической установки убывает с ростом числа Рейнольдса.
\end{abstract}

Ключевые слова: ветроэнергетическая установка, быстроходность ветроэнергетической установки, число Рейнольдса, эффект Магнуса.

DOI: 10.21883/PJTF.2021.20.51616.18645

Ветроэнергетическая установка с лопастями в виде вращающихся цилиндров, работающая на основе эффекта Магнуса, имеет ряд преимуществ перед существующими ветроэнергетическими установками. Сила Магнуса, возникающая на вращающемся цилиндре из-за асимметрии отрыва потока от его поверхности, может быть на порядок выше подъемной силы традиционной лопасти [1-5]. Таким образом, можно ожидать нарастания движущей силы ветрового колеса, а также других эксплуатационных характеристик. У традиционных лопастных ветроэнергетических установок существует недостаток в виде низкой эффективности работы при наиболее повторяемых скоростях ветра $V<6-7 \mathrm{~m} / \mathrm{s}$, что связано с малым коэффициентом подъемной силы лопасти $C_{y} \leqslant 1$. Для ветроэнергетических установок с лопастями в виде вращающихся цилиндров минимальный порог рабочей скорости ветра составляет $2-4 \mathrm{~m} / \mathrm{s}$, а максимальный достигает $40 \mathrm{~m} / \mathrm{s}$. Дополнительным преимуществом ветроэнергетической установки, работающей на основе эффекта Магнуса, является аэродинамическое саморегулирование вращения ветрового колеса, предотвращающее его чрезмерную раскрутку и разрушение за счет возникающих центробежных сил $[6,7]$.

Основными аэродинамическими характеристиками ветроколеса с цилиндрическими лопастями, обеспечивающими эффективность работы, являются относительная скорость вращения цилиндров, быстроходность ветроколеса, коэффициент использования энергии ветра, его мощность и затраты мощности на вращение цилиндров [8-10].
Цель настоящей работы - исследование изменений аэродинамических характеристик: быстроходности ветроэнергетической установки, коэффициента использования энергии ветра, а также получение расчетных данных, доказывающих сравнительную эффективность таких установок.

Для исследования процесса преобразования ветровой энергии воздушного потока в электрическую энергию в лабораторных условиях был создан экспериментальный образец ветроэнергетической установки с лопастями в виде вращающихся цилиндров постоянного сечения с гладкой поверхностью.

Эксперименты по исследованию аэродинамических характеристик проводились в естественных условиях воздушного потока. Фотография экспериментальной ветроэнергетической установки приведена на рис. 1 .

Аэродинамические параметры потока изменялись в следующих пределах:

1) первый диапазон - малые скорости ветра $(2-5 \mathrm{~m} / \mathrm{s})$;

2) второй диапазон - средние скорости ветра $(5-10 \mathrm{~m} / \mathrm{s})$;

3) третий диапазон - высокие скорости ветра (свыше $10 \mathrm{~m} / \mathrm{s})$.

При этом скорость вращения цилиндров варьировалась от 300 до $700 \mathrm{rpm}$.

Направления вращения могли быть сонаправленными и противоположно направленными.

Быстроходность ветроэнергетической установки $Z$ определяется как отношение скорости вращения конца 


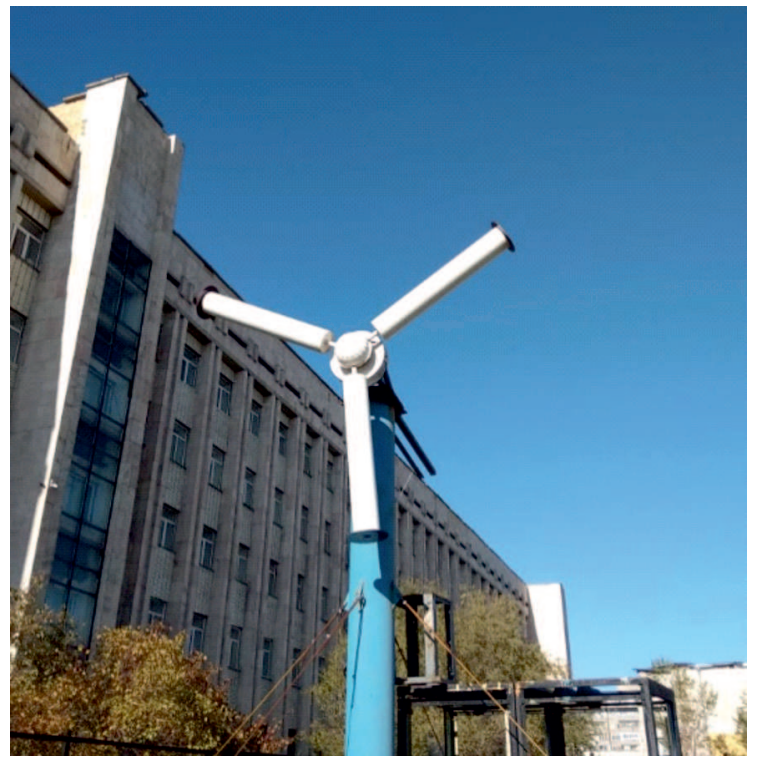

Рис. 1. Экспериментальная ветроэнергетическая установка.

лопасти к скорости набегающего потока

$$
Z=\frac{2 \pi R n}{60 V}
$$

где $R$ - радиус ветроколеса $[\mathrm{m}], n-$ число оборотов в минуту, $V-$ скорость воздушного набегающего потока $[\mathrm{m} / \mathrm{s}]$.

Для измерения числа оборотов использовался цифровой лазерный фототахометр АТ-8. Скорость набегающего воздушного потока измерялась чашечным анемометром Skywatch Atmos.

Число Рейнольдса определяется по формуле

$$
\operatorname{Re}=\frac{\rho D V}{\mu},
$$

где $\rho-$ плотность среды $\left[\mathrm{kg} / \mathrm{m}^{3}\right], D-$ диаметр ветроэнергетической установки $[\mathrm{m}], \mu-$ динамическая вязкость среды $[\mathrm{Pa} \cdot \mathrm{s}]$.

Коэффициент использования энергии ветра $\xi$ определяет отношение работы, развиваемой крутящим ветроколесом, к энергии ветрового потока, имеющего поперечное сечение, равное этой поверхности, и находится по следующей формуле [9]:

$$
\xi=C_{x}\left(1-\frac{u}{V}\right)^{2} \frac{u}{V}
$$

где $C_{x}-$ аэродинамический коэффициент лобового сопротивления, $u-$ скорость перемещения цилиндра $[\mathrm{m} / \mathrm{s}]$.

Для расчета аэродинамического коэффициента лобового сопротивления $C_{x}$ в ходе выполнения работы использовалась следующая формула:

$$
C_{x}=\frac{2 F_{x}}{\rho u^{2} S} .
$$

На основе экспериментальных данных проведен расчет значения быстроходности ветроэнергетической установки $Z$ по формуле (1) и числа Рейнольдса по формуле (2), где диаметр ветроэнергетической установки $D=2.372 \mathrm{~m}$. Вязкость воздуха равна $1.795 \cdot 10^{-5} \mathrm{~Pa} \cdot \mathrm{s}$, плотность составляет $1.225 \mathrm{~kg} / \mathrm{m}^{3}$. Число оборотов цилиндра в минуту $(n)$ изменялось от 300 до 700 .

На рис. 2, $a$ изображена зависимость быстроходности ветроэнергетической установки от числа Re, рассчитанная по экспериментальным данным. Расчеты показывают, что увеличение числа оборотов и уменьшение числа Рейнольдса ведут к росту быстроходности ветроэнергетической установки, что не противоречит результатам работы [5]. Как видно из рис. 2, $a$, максимальная величина быстроходности $(Z=2.85)$ достигается при $n=700$ и $\operatorname{Re}=5 \cdot 10^{5}$. Это позволяет сделать вывод, что ветроэнергетическую установку можно отнести к классу тихоходных установок [9].

Далее проведены теоретические исследования зависимости значения коэффициента использования энергии ветра от скорости набегающего потока ветроэнергетической установки, рассчитанные по формуле (3).

На рис. $2, b$ представлена зависимость коэффициента использования энергии ветра от вариации скорости набегающего потока ветроэнергетической установки, которая носит монотонный характер убывания с ростом $V$.

При значении скорости набегающего потока $V=3 \mathrm{~m} / \mathrm{s}$ и $n=700$ представляется возможность получить максимальный коэффициент использования энергии ветра $\xi$, равный $50 \%$ (рис. $2, b$ ). Согласно теории идеального ветроколеса и законам сохранения энергии и импульса,
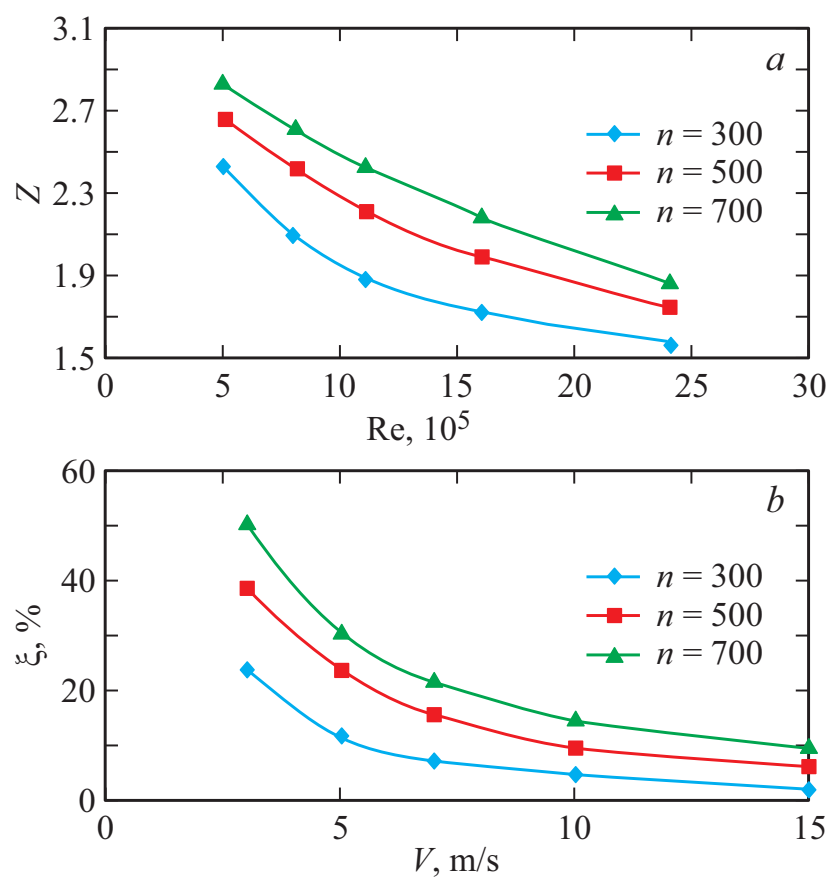

Рис. 2. Зависимости быстроходности от числа Рейнольдса $(a)$ и коэффициента использования энергии ветра от скорости набегающего потока ветроэнергетической установки $(b)$. 


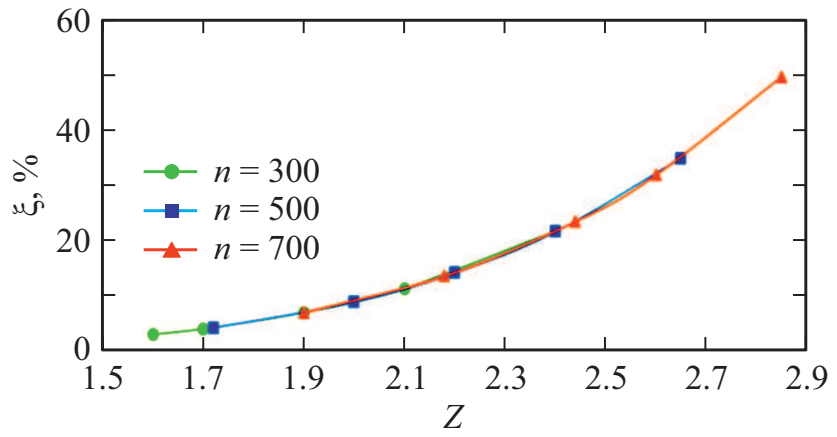

Рис. 3. Зависимость коэффициента использования энергии ветра от быстроходности ветроэнергетической установки.

максимальный коэффициент $\xi$ равен $59.3 \%$, поэтому полученные данные свидетельствуют о высокоэффективной работе установки за счет образующего турбулентного вихревого потока вокруг крутящего цилиндра. Если обозначить $u / V$ в формуле (3) через $e$, подставить эту величину в уравнение и решить его, получим доказательство того, что для приобретения максимального значения $\xi$ цилиндр должен перемещаться со скоростью $u=1 / 3 V[9]$.

На основе полученных результатов, представленных на рис. 2, $a$ и $b$, был проведен расчет коэффициента использования энергии ветра от быстроходности ветроэнергетической установки (рис. 3). Как видно из рис. 3, эффективность использования энергии ветра можно представить степенной функцией быстроходности ветроэнергетической установки

$$
\xi=31.53 Z^{4.8325 \%} \%
$$

Из данной зависимости следует, что эффективность использования энергии ветра растет пропорционально быстроходности ветроэнергетической установки в степени, близкой к 5 .

На основе полученных результатов экспериментальных и теоретических исследований можно сделать следующие выводы.

1. Установлена связь быстроходности, представляющей собой угловую скорость ветроэнергетической установки, с числом Рейнольдса, который обратно пропорционален ей. Полученное значение $Z_{\max }=2.85$ доказывает, что ветроэнергетическая установка, предложенная авторами, относится к классу тихоходных установок, обладающих большим пусковым моментом и малой стартовой скоростью ветра, которая приемлема для надежного и эффективного использования энергетических ресурсов ветра.

2. Получена зависимость коэффициента использования энергии ветра, определяющего среднюю выработку электроэнергии, от скорости набегающего потока ветроэнергетической установки. Найдено, что максимальное значение $\xi$ равно $50 \%$, что доказывает высокую эффективность работы ветроэнергетической установки с цилиндрическими лопастями за счет образующего турбулентного вихревого потока вокруг крутящего цилиндра.

3. Установлено, что каждому значению быстроходности ветроэнергетической установки соответствует характерное значение коэффициента использования энергии ветра, которое представляет собой степенную функцию $\xi=31.53 Z^{4.8325 \%} \%$.

Таким образом, полученные результаты в полном объеме могут быть использованы при разработке и создании ветроэнергетических установок для малых скоростей на основе эффекта Магнуса, которые позволяют наиболее рационально и эффективно использовать энергетические ресурсы ветра.

\section{Конфликт интересов}

Авторы заявляют, что у них нет конфликта интересов.

\section{Список литературы}

[1] Н.К. Танашева, Б.Р. Нусупбеков, А.Н. Дюсембаева, Н.Н. Шуюшбаева, ЖТФ, 89 (7), 1006 (2019). DOI: $\quad$ 10.21883/JTF.2019.07.47788.415-18 [N.K. Tanasheva, B.R. Nusupbekov, A.N. Dyusembaeva, N.N. Shuyushbayeva, Tech. Phys., 64 (7), 947 (2019). DOI: 10.1134/S1063784219070247].

[2] N.M. Bychkov, A.V. Dovgal, V.V. Kozlov, J. Phys.: Conf. Ser., 75, 012004 (2007). DOI: 10.1088/1742-6596/75/1/012004

[3] Н.М. Бычков, Теплофизика и аэромеханика, 12 (1), 159 (2005). https://www.sibran.ru/upload/iblock/744/ 744d9166b640183e4664f1552439f889.pdf

[4] О.Б. Соломенкова, И.М. Павленко, Вестн. Саратов. гос. техн. ун-та, 4 (2), 49 (2010). https://www.elibrary.ru/ download/elibrary_16521865_98605782.pdf

[5] Н.М. Бычков, Теплофизика и аэромеханика, 15 (2), 583 (2008). https://www.sibran.ru/upload/iblock/507/ 507a92e210e9f16e4200317b8d14cf63.pdf

[6] N.K. Tanasheva, L.V. Chirkova, A.N. Dyusembaeva, K.K. Sadenova, J. Eng. Phys. Thermophys., 93, 551 (2020). DOI: $10.1007 / \mathrm{s} 10891-020-02152-1$

[7] Н.К. Танашева, Н.Н. Шуюшбаева, Э.К. Мусенова, Письма в ЖТФ, 44 (17), 65 (2018). DOI: 10.21883/PJTF.2018.17.46572.17240 [N.K. Tanasheva, N.N. Shuyushbayeva, E.K. Mussenova, Tech. Phys. Lett., 44 (9), 787 (2018). DOI: 10.1134/S1063785018090134].

[8] Я.И.Шефтер, Использование энергии ветра (Энергоатомиздат, М., 1983).

[9] Е.М. Фатеев, Ветродвигатели и ветроустановки (Сельхозгиз, М., 1948).

[10] С.И. Исатаев, О. Жангунов, в сб.: Исследование процесса переноса (Алма-Ата, 1985), с. 17. 